\title{
MÉTODO CLÍNICO: DESENVOLVIMENTO MORAL EM QUILOMBOLAS
}

\section{MÉTODO CLÍNICO \\ DESARROLLO MORAL EN QUILOMBOLAS}

Juliana Berg

Bolsista Capes, Doutorado, Universidade Federal do Paraná - UFPR

Carla Luciane Blum Vestena

Universidade Estadual do Centro-Oeste - Unicentro;

Universidade Federal do Paraná - UFPR

\begin{abstract}
Resumo
O presente trabalho traz reflexões preliminares de estudo teórico e exploratório por método clinico realizado em escolas da Colônia Vitória, município de Guarapuava, estado do Paraná, Brasil, que recebem crianças advindas da comunidade quilombola Invernada Paiol de Telha. Pretende-se refletir sobre esse método por meio da compreensão moral ambiental dessas crianças quilombolas. Baseado na obra do autor construtivista Jean Piaget e considerando a percepção ambiental como parte da conexão existente entre a formação do juízo moral e dos valores quilombolas que são construídos de forma a existir uma compreensão do meio ambiente enquanto meio onde há uma relação dinâmica de troca. Entende-se que o método clínico viabilizou essa analise quando colocou em movimento o pensar infantil ativando o julgamento moral para as questões ambientais e também quando evidenciou o silêncio por opressão vivida pelas meninas da comunidade.
\end{abstract}

Palavras-chave: Meio ambiente. Quilombolas. Método clínico. Jean Piaget. Brasil.

\section{Resumen}

El presente trabajo trae reflexiones preliminares de estudio teórico y exploratorio por método clínico realizado en escuelas de la Colônia Vitória, municipio de Guarapuava, estado de Paraná, Brasil, que reciben niños de la 
comunidad quilombola Invernada Paiol de Telha. Se pretende reflexionar sobre este método a través de la comprensión moral ambiental de estos niños quilombolas. Basado en el trabajo del autor constructivista Jean Piaget y considerando la percepción ambiental como parte de la conexión existente entre la formación del juicio moral y los valores de quilombola que se construyen de tal manera que hay una comprensión del medio ambiente como un medio donde existe una relación de intercambio dinámico. Se entiende que el método clínico hizo que este análisis cuando puso en marcha el pensamiento infantil, activando el juicio moral para lascuestiones ambientales y también cuando evidenciaba el silencio por opresión experimentada por las niñas de la comunidad.

Palabras clave: Medio ambiente. Quilombolas. Método clínico. Jean Piaget. Brasil.

\section{Introdução}

No Brasil, estado do Paraná, região do município de Guarapuava encontra-se a comunidade quilombola Invernada Paiol de Telha, localizada em terras denominadas Distrito de Entre Rios, Colônia Vitória. São aproximadamente 68 famílias remanescentes de quilombo, onde residem perto de 50 crianças. Uma comunidade em situação bastante complexa por sua luta pela garantia da terra e pela marcação dual das culturas existentes, onde muitos dos habitantes, colonizadores da região, são de descendência alemã suábia. Outro aspecto importante em Paiol de Telha é a ausência de uma escola no espaço quilombola o que faz com que as crianças se desloquem para estudar na colônia.

Guardados os possíveis efeitos culturais positivos dessa interação, que não é foco desse estudo, podemos pensar que essa troca entre as culturas provoca o enxergar seu lugar de forma diferente dos demais que não é apenas uma questão de ponto de vista, mas sim de uma construção que depende de muitos fatores.

$\mathrm{O}$ relato aqui apresentado é recorte de pesquisa maior denominada "Moralidade e Conhecimento Socioambiental de Meninos e Meninas da Comunidade Quilombola Invernada Paiol de Telha", iniciada no primeiro semestre do ano de 2013 e financiada pelo Conselho Nacional de Desenvolvimento Científico e Tecnológico - CNPQ, através da Chamada Universal - MCTI/CNPq/SPM/MDA N ³2/2012. 
Objetiva contextualizar a importância do método clínico como metodologia de pesquisa capaz de colocar em movimento o pensar e o julgamento da criança, como também relatar que a partir deste pôde-se descortinar opressão vivida por meninas quilombolas em sala de aula. Nesse sentido proporciona o pensar o currículo sob perspectiva nova, colocando em questão: pesquisa, conhecimento e percepção pela diversidade encontrada a partir de nossas descobertas em ambiente escolar.

\section{Juízo Moral da Criança}

A construção da autonomia moral e ética é possível a todos os indivíduos, pois é fruto de sua gênese (PIAGET, 1932). Ela depende de muitos fatores como um crescimento orientado, um processo de construção operacional equilibrado e adequado à faixa etária da pessoa e principalmente da interação e mediação com o meio e tudo que nele habita.

Segundo Piaget (1932, p.11),

[...] as regras morais, que a criança aprende a respeitar, lhes são transmitidas pela maioria dos adultos, isto é, ela as recebe já elaboradas, e, quase sempre, elaboradas, nunca na medida de suas necessidades e de seu interesse, mas de uma vez só e pela sucessão ininterrupta das gerações adultas anteriores.

Nesse sentido ganham valor dois aspectos fundamentais no que se refere à aprendizagem das regras morais: o respeito que as crianças têm pelo conteúdo das regras e o respeito que tem pelos adultos que repassam as regras, sendo estes um modo de sentir que interferirá diretamente na construção de um ser humano capaz de compreender e agir moralmente (PIAGET, 1932).

O respeito surge como sentimento fundamental para a aquisição das noções morais podendo ser interpretado de formas diferentes. O respeito unilateral, ou seja, aquele que implica numa relação de desigualdade como o forte pelo fraco, o rico pelo pobre, o adulto pela criança e assim por diante, onde se concebe a coação do superior em relação ao inferior é uma das formas de respeito comuns pela prática da autoridade (PIAGET, 1932).

Porém, a relação de coação numa construção sadia do juízo moral da criança não pode ser entendida como autoritarismo, ela é necessária mas não pode manter-se no tempo de crescimento do indivíduo - maturação biológica (seu amadurecimento na capacidade de juízo) - ou seja a criança deve compreender a relação de respeito pelo adulto que o instrui 
como necessária, pois essa relação possibilitará um melhor aproveitamento do conhecimento repassado, que servirá de arcabouço teórico e prático de sua formação (PIAGET, 1932).

Portanto, quando mencionamos a autoridade fazemos referência à instrução, ao repasse do conhecimento pelo adulto que domina o conteúdo e o conhecimento para criança tanto no ambiente familiar, cotidiano, quanto na escola. Já o respeito mútuo prevê uma relação de cooperação onde os indivíduos se respeitam reciprocamente. Nessa etapa do desenvolvimento do juízo moral, a criança inicia um exercício de justiça contrariando o respeito unilateral exteriorizado imposto pela regra do certo e errado. Surgem os conflitos, as dúvidas, os questionamentos, os confrontos, principalmente com a autoridade adulta.

Segundo Piaget (1932, p.279),

A moral da autoridade, que é a moral do dever e da obediência, conduz, no campo da justiça, à confusão do que é justo como o conteúdo da lei estabelecida e aceitação da sanção expiatória. A moral do respeito mútuo, que é a do bem (por oposição ao dever) e da autonomia, conduz, no campo da justiça, ao desenvolvimento da igualdade, noção constitutiva da justiça distributiva, e da reciprocidade.

Diante disso, necessário é saber que existem três tendências morais possíveis no que se refere ao desenvolvimento moral da criança definidas por Piaget (1932): a anomia, a heteronomia e a autonomia. A anomia é a ausência total de autonomia, o que nos leva a pensar que a moral não é inata; A heteronomia desenvolvida por uma relação de coação é relacionada ao respeito unilateral às regras; e a autonomia é viabilizada pelo respeito mútuo, pela cooperação nas relações, construída num processo de interação da criança com o meio, ou seja interiorizada.

Para analisar como se processa o respeito às regras, Piaget (1932) considerou para sua pesquisa, desenvolvida ao longo de mais de 50 anos uma condição fundamental: a necessidade inicial de se pensar como as crianças pensam, ou seja, no nível etário em que se encontram e considerando o lugar onde estão inseridas. Isso porque essas variantes poderiam mudar o resultado da pesquisa, podendo assim ser esse influenciado pela cultura e experiência de cada sujeito, bem como do pesquisador.

Ele buscou nos jogos infantis, assim como na proposição de dilemas, considerados parte do cotidiano da criança e onde as regras são fundamentais para que a atividade aconteça, um meio de observar e estudar como se dá o julgamento moral da criança, A importância da 
regra está em ser ela que "permite dar corpo à moral, situá-la no tempo e no espaço" (LA TAILLE, 2006, p. 74).

Além de observar, Piaget (1932) também jogava e dialogava com as crianças e durante a brincadeira conversava com elas sobre as regras do jogo, assim como propunha questões reflexivas aos dilemas. Essa interação, vivência em comum, demonstrou que as crianças tinham a prática e a consciência da regra e evidenciou que ambas aconteciam em estágios diferentes.

Piaget (1932) descobriu que as crianças pequenas até 3 anos de idade jogam individualmente e apenas percebem as peças e o espaço do jogo, mas aleatoriamente brincam da forma que quiserem. Testam mais a interação motora não se preocupando com as regras sociais ou individuais.

Já as crianças de 3 a 6 anos de idade utilizam-se da vivência coagida no seu cotidiano e reproduzem os maiores durante o seu jogar, ao mesmo tempo em que buscam novas alternativas que atendam a seu interesse pessoal, uma característica egocêntrica que também influencia sua capacidade de jogar individualmente, como se mesmo jogando juntos as regras fossem individuais (PIAGET, 1932).

Para Piaget (1932 p. 81), "o egocentrismo infantil é em sua essência uma indiferenciação entre o eu e o meio social" no qual em seu estágio radical (egocentrismo integral) há "falta de consciência do ego" de sua subjetividade e a criança não percebe o outro. Dessa maneira,

Constitui-se em uma espécie de centralização do pensamento - no sentido de uma ausência de toda relatividade intelectual e de todo sistema racional de referência -, e que toma por única realidade aquela que aparece à percepção própria, coordenando única e somente a própria perspectiva (PIAGET, 1923/1999). Visto que o universo inteiro é considerado em comunhão com o ego e a ele obediente, seus desejos e as ordens do ego são tidos por absolutos, havendo então, uma confusão entre as contribuições do exterior e as contribuições do interior. (SASSO \& MORAIS, 2013, p.24).

Entre 7 e 10 anos as crianças percebem que jogar sozinho, para si, causa conflito e começam a se organizar para o jogo, começam a entender a necessidade da regra e criam meios de controle mútuo, o que Piaget chamou de cooperação nascente (PIAGET, 1932).

Após os 11 anos de idade as regras ganham mais importância, pois as crianças percebem sua utilidade e necessidade do ponto de vista da justiça fazendo questão de utilizar 
seu tempo de jogo para o detalhamento das regras para discussão de novas situações que vão acontecendo durante o jogar (PIAGET, 1932).

Com esses levantamentos pode-se afirmar que há consciência da regra pelas crianças, mas que essa consciência acontece em etapas e formas diferentes de desenvolvimento como detalhado acima. Há também a consciência da transgressão às regras tido como não aceitável, um crime, pelas crianças principalmente entre os 7 e 9 anos. Outra característica nessa faixa etária é a aceitação da inovação como parte do jogo, desde que acordado entre o grupo.

Quando atingem os 11 anos chega-se a uma consciência da regra como algo elaborado e construído, não algo fruto de coação apenas, mas por sua condição igualitária entre indivíduos, construída por meio da cooperação mútua, de todos e para todos (PIAGET, 1932).

Para Piaget (1932), a prática da regra leva a consciência e o conhecimento não é uma cópia da realidade. Conhecer um meio, conhecer um acontecimento não é simplesmente olhar para ele e ter uma cópia ou imagem mental, tal como ele. Conhecer um meio é agir sobre ele, conhecer é modificar, transformar e entender o processo dessa transformação e como consequência entender como o meio é construído.

\section{Crianças quilombolas e seus valores morais}

A discussão sobre a construção dos sujeitos, sua identidade e sua relação com os demais são necessárias para que possamos contextualizar os valores aplicados em comunidades ou lugares. Faz parte de nosso entendimento sobre o múltiplo e expande nosso olhar, nossa percepção para o outro.

Quando tratamos especificamente dos povos quilombolas podemos falar sobre várias temáticas, pois se sabe que a multiplicidade, étnica e cultural brasileira é uma característica conhecida em várias análises das ciências sociais e estudos educacionais. Entretanto, a percepção concreta desta multiplicidade no cotidiano populacional por meio de ações presentes no dia-a-dia dos grupos é pouco significativa.

Nesse sentido, destaca-se aqui a emergência das comunidades remanescentes de quilombos que no imaginário nacional teriam desaparecido do Brasil junto com o sistema escravocrata, o que não ocorreu e forçou seu reconhecimento oficialmente em 1988, principalmente com a afirmação de seus direitos territoriais por meio do Artigo 68 do Ato das Disposições Constitucionais Transitórias da Constituição - ADCT (BRASIL, 1988). 
Para Associação Brasileira de Antropologia (ABA) o quilombo hoje tem significado ampliado sendo que

O termo quilombo tem assumido novos significados na literatura especializada e também para grupos, indivíduos e organizações. Vem sendo ressemantizado para designar a situação presente dos segmentos negros em regiões e contextos do Brasil. Contemporaneamente, quilombo não se refere a resíduos ou resquícios arqueológicos de ocupação temporal ou de comprovação biológica. Não se trata de grupos isolados ou de população estritamente homogênea, nem sempre foram constituídos a partir de movimentos insurrecionais ou rebelados. Sobretudo consistem em grupos que desenvolveram práticas cotidianas de resistência na manutenção e na reprodução de seus modos de vida característicos e na consolidação de território próprio. A identidade desses grupos não se define por tamanho e número de membros, mas pela experiência vivida $\mathrm{e}$ as versões compartilhadas de sua trajetória comum e da continuidade como grupo. Neste sentido, constituem grupos étnicos conceitualmente definidos pela antropologia como um tipo organizacional que confere pertencimento por meio de normas e meios empregados para indicar afiliação ou exclusão. (O’DWYER, 1995, p. 2)

No Brasil, o contexto escolar dessas comunidades é motivo de muitas discussões e ajustes, visto que muitas das crianças e adolescentes remanescentes não possuem escolas na comunidade onde vivem, tendo que estudar nas proximidades. Segundo o Censo Escolar de 2004, existem 49.722 estudantes matriculados em 374 escolas localizadas em áreas de remanescentes de quilombos, sendo que $62 \%$ das matrículas estão na região Nordeste.

Mesmo sendo esse um postulado das Diretrizes Curriculares Nacionais para a Educação Escolar Quilombola que segue as orientações das Diretrizes Curriculares Nacionais Gerais para a Educação Básica é muito comum encontrar essas crianças quilombolas itinerantes em busca da educação em outras localidades.

A Educação Escolar Quilombola é desenvolvida em unidades educacionais inscritas em suas terras e cultura, requerendo pedagogia própria em respeito à especificidade étnico-cultural de cada comunidade e formação específica de seu quadro docente, observados os princípios constitucionais, a base nacional comum e os princípios que orientam a Educação Básica brasileira. $\mathrm{Na}$ estruturação e no funcionamento das escolas quilombolas, deve ser reconhecida e valorizada sua diversidade cultural. (BRASIL, 2013, p. 42)

Para as comunidades quilombolas a Educação passa pelo reconhecimento dos valores, pois esses são formas de introduzir e fortalecer seu cotidiano e sua cultura, sendo concebidos também com base na matriz africana estando interligados.

A relação da percepção ambiental e de valores é mais sensível quando pode-se pensar que para o quilombola valores estão interligados. Eles se relacionam como se respeitassem

Revista RBBA Revista Binacional Brasil Argentina 
uns aos outros sendo todos importantes para a construção de um ambiente que prospere a cultura afro-brasileira.

\section{Método Clínico}

Esclarecidas nossas bases conceituais e epistemológicas, importante reforçar que as concepções de Piaget (1932) foram escolhidas para subsidiar a pesquisa junto as crianças quilombolas por mostrar que o sujeito constrói ou desenvolve o seu conhecimento a partir da interação com o ambiente - sujeito - objeto.

Segundo Piaget (1956, p. 14), o conhecimento “[...] é primeiro, uma ação com o objeto e neste sentido implica em suas próprias raízes uma dimensão motriz permanente, representada ainda nos níveis mais elevados [...]”. E seu "ponto de partida está constituído pelas ações do sujeito com o real" (PIAGET, 1949, p. 341).

Foi Piaget (1932) quem deu um novo sentido ao método clínico ao utilizá-lo e adaptálo em pesquisas com crianças analisando seus processos cognitivos com relação às representações de mundo, de espaço, de real, de construção da inteligência, de julgamentos morais, de noções de justiça, dentre outros.

Segundo Delval (2002, p. 53) "Piaget teve o mérito de convertê-lo em procedimento geral para penetrar nos recônditos do funcionamento da mente humana". Para ele este método clínico é utilizado para o estudo do pensamento da criança através de procedimentos de coleta e análise de dados. Para Campos (1932), somente o método clínico permite propor problemas, formular hipóteses, controlar cada uma delas, pondo-as em contato com as reações provocadas pela conversa.

Esta pesquisa aconteceu em Escola Municipal, Nível Fundamental II, com 30 meninos e meninas, idade entre 10 e 12 anos, sendo parte da colônia e parte da comunidade quilombola. Foram realizadas exibições de vídeos ambientais de curta duração, sendo que em seguida foram colocadas situações dilema, quando as crianças receberam informações a respeito da poluição das águas e morte de animais silvestres, bem como a destinação do lixo e a coleta seletiva. As crianças foram questionadas sobre qual a melhor solução para a questão proposta.

Durante a coleta procurou-se acompanhar o pensamento do sujeito realizando novas perguntas/ações tentando compreender de que forma a criança representava ou organizava seus pensamentos e ações, o que possibilitou analise da compreensão do que é real, exposto 
pelos meios de comunicação, do que é intrínseco ao sujeito de pesquisa, seus valores e sua cultura. Com isso, pôde-se compreender como se deu a interpretação pelas crianças.

Optou-se por executar a pesquisa em sala de aula por ser esse um ambiente comum de escolarização para as crianças quilombolas e por estarem em convivência com outras crianças que não da comunidade o que evidenciaria o quanto seus valores se mantem em ambiente cultural adverso.

As ações foram analisadas conforme cita Delval (2002), considerando o sujeito como único, que é uma unidade e que tem coerência interna, porém não se centra no peculiar e sim no universal desta criança como sujeito epistêmico, um sujeito que produz conhecimentos.

As reflexões foram feitas a partir de um protocolo de intervenção onde foram colocadas situações dilema a partir de questões que orientaram a coleta dos dados. Sendo basicamente entrevista semiestruturada em que:

Perguntas básicas comuns a todos os sujeitos, que vão sendo ampliadas e complementadas de acordo com as respostas dos sujeitos para poder interpretar o melhor possível o que vão dizendo. As respostas orientam o curso do interrogatório, mas se retorna aos temas essenciais estabelecidos inicialmente. É o tipo de entrevista mais empregado na pesquisa (DELVAL, 2002, p. 147)

Portanto, consideramos estudo qualitativo, que segundo Fachin (2006), não são medidas ou contatas e sim descritas de forma analítica. Pesquisas com esta abordagem são caracterizadas pela intensa presença do pesquisador. É um dos caminhos para se desenvolver uma investigação, pois possibilita entender a complexidade das relações sociais, o significado e a intenção dos atos.

É também um estudo exploratório transversal, pois estuda diferentes grupos de crianças com idades distintas verificando quais são as condutas e atitudes comuns a elas, permitindo o acompanhamento da evolução dos dados em um período restrito examinando muitos sujeitos (DELVAL, 2002).

Segundo Delval (2002), após a coleta há necessidade de extrair o máximo possível de informações dos dados. Além disso, o autor cita que ao iniciar a análise dos dados obtidos pelo método clínico devemos nos preocupar com a análise qualitativa para que não se percam dados valiosos na categorização, tornando-os intuitivos e muito simples. 
Planejamos a aplicação da pesquisa no tempo da aula de 50 minutos, de forma a obtermos a participação e o julgamento moral das crianças a respeito do tema: Destinação de Lixo: Plástico. Em seguida a pesquisa assumiu a seguinte dinâmica:

1. Primeiro foi repassada lista de presença na qual os alunos se identificaram com nome, idade e local. Assim, pudemos localizar as crianças quilombolas sem que houvesse a possibilidade de rotulação ou possível segregação.

2. Foi então, realizada exibição de vídeos de curta duração com caráter informativo sobre a temática do plástico, enquanto resíduo. No vídeo El Plástico Mata - versão em portuguêsi feito pela produtora, Equilíbrio Marinho TV que mostra o trabalho do fotógrafo Chris Jordan sobre o que está acontecendo na ilha de Midway no Oceano Pacífico Norte. Neste local, que fica a 2000 milhas do continente, plásticos estão sendo acumulados trazidos por correntes marinhas. As imagens mostram carcaças de aves que se alimentaram desse plástico. O vídeo não possui narração, apenas imagens, que demonstram como estão morrendo as aves dessa localidade. Quando as carcaças dos animais são fotografadas podese ver o que eles ingeriram, acreditando que estariam se alimentando de organismos marinhos.
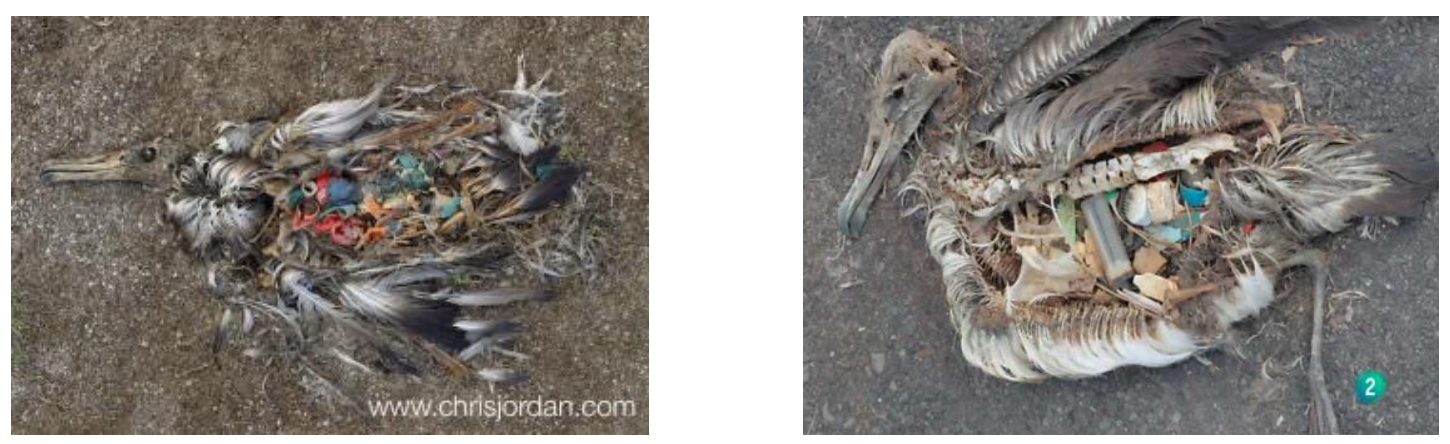

Figura 1: El Plástico Mata, de Chris Jordan.

3. Após a exibição do vídeo, por meio de roteiro predeterminado, colocamos a seguinte situação dilema para as crianças:

Sacolas plásticas vão motivar a morte de cinco aves que moram na costa da praia, mas você tem a chance de evitar a tragédia acionando uma buzina que arrastará o barco para outra região, onde a sacola plástica mutilará apenas uma ave. Você mudaria o trajeto do barco, acionando a buzina, salvando cinco aves e matando uma ave?

4. Aguardamos alguns minutos para ver se as crianças se manifestavam a respeito da situação dilema. 
5. Então, com a participação de algumas crianças iniciamos o protocolo de questionamentos acerca do assunto assistido e do dilema proposto:

Quem acionaria a buzina? Quem não acionaria? Porque acionaria a buzina? Porque não acionaria? Mas, morrerão 5 aves se a buzina não for acionada! Mas, morrerá uma ave se a buzina for acionada! Qual a decisão da turma? Alguma outra alternativa?

6. Logo em seguida foi exposto o segundo vídeo apresentando a reportagem de Rodrigo Alvarez exibida no programa Fantástico, pela Rede Globo de Televisão que conta por meio de narração a história de um lugar localizado entre o Havaí e a costa da Califórnia nos Estados Unidos conhecido como o Lixão do Pacífico. Nesse local estão sendo acumuladas toneladas de lixo, especialmente o plástico trazido de vários continentes por uma condição natural dos ventos e da maré matando aves e criando anomalias genéticas nos animais marinhos. ${ }^{\text {ii }}$

\section{Questionou-se:}

1. Quando as pessoas jogam lixo nas ruas o que você acha que acontece? 2. Que tipo de lixo tem sido jogado nas ruas? 3. Os restos de alimentos podem ser reaproveitados? Se sim, Como? Se não, por quê? 4. No caso do papel você sabe me contar como que ele é feito? Se sim, conte-me como isso ocorre. 5. Você sabe do que é feita a garrafa PET? Se sim, conte-me como? 6. E o vidro, como ele é feito? 7. O que acontece com o papel, o plástico e o vidro quando são jogados em terrenos abandonados? 8. Qual garrafa se decompõe mais rápido num terreno abandonado, a de plástico ou a de vidro? Por quê? 9. E no caso de uma garrafa de plástico inteira e uma de vidro quebrado (em cacos pequenos) jogadas num terreno abandonado, qual delas você acha que se decompõe mais rápido? Por quê? 10. Os lixos jogados nas ruas podem ser reaproveitados? Se sim, conte-me como? Se não, por quê?

8. A cada manifestação de julgamento, sempre seguindo o roteiro, íamos colocando novos questionamentos, nunca afirmações, acompanhados de colocações como:

Mas porquê? Porque você pensa assim? Você tem certeza de sua decisão? Mas se fizéssemos diferente o que aconteceria? etc.

Optou-se pelos vídeos por ser uma linguagem que atinge a maioria dos alunos em sala de aula, por trazer situações específicas relacionadas ao tema do plástico, enquanto resíduo e por ser um meio de sensibilização conhecido de todos situando as crianças ao assunto. 
Elencou-se como tema ambiental para ser avaliado, nessa linha de compreensão, a destinação do plástico, por variadas razões: Pelo fato de no Quilombo Paiol de Telha, suas crianças manterem contato rotineiro com a Colônia Vitória, o que já mudou os hábitos de consumo e portanto de pensar seus resíduos; Por ser a destinação de resíduos um dos temas que mais desperta a preocupação local e mundial; Para o fato de que para os quilombolas por conta de sua cultura essa relação com resíduos possa se demonstrar diferenciada; E por ser esta uma pesquisa aplicada em ambiente escolar onde estão crianças da colônia e quilombolas, sendo esse um tema comum a ambos. Toda intervenção foi fotografada e gravada em vídeos que foram catalogados para posterior análise.

\section{Resultados pela Aplicação do Método Clínico}

$\mathrm{Na}$ escola, as crianças receberam bem o dilema, aceitaram participar dos questionamentos propostos e demonstraram o desenvolvimento de seu julgamento moral em acordo com sua faixa etária, como preconizado por Piaget (1932).

Após a exibição do primeiro video, sobre a morte das aves, foi aplicado dilema cuja parte da transcrição íntegra segue abaixo. Consta a sigla Af para menina e Am para menino. AQf refere-se à menina quilombola e AQm menino quilombola, porém não tivemos manifestação das meninas quilombolas.

Pesquisadora: Quem apertaria a buzina? Levantem a mão.

29 levantaram. 13 meninas e 16 meninos

Pesquisadora: E quem não apertaria? É uma opção. Eu vou deixar. Alguém faria

isso?

A maioria fez não com a cabeça. Ninguém levantou o braço.

Pesquisadora: E alguém ainda ficou com dúvida?

A maioria consentiu, sim, com a cabeça.

Pesquisadora: E quem apertaria, apertaria por quê?

Am1: Por causo que se apertar vai matar só um.

Pesquisadora: Tá mais por quê?

Af1: Melhor matar só um do que cinco.

Pesquisadora: Mas será que havia outro motivo, ainda, mais forte que esse?

Am1: Caso que a gente não polui.

Pesquisadora: Como?

Aml: Que se a gente polui vai matar os bichos.

Pesquisadora: Quem teria uma outra alternativa? Porque ainda sim uma ave morreria.

Af2: É apertar a buzina e matar só uma ave. 
Pesquisadora: Quem tem mais ideia? Será que não tem outra alternativa para fazer? Uma ideia criativa para evitar tudo isso?

Menina Quilombola 1: É reciclar o lixo, causo que aí não tem lixo.

Pesquisadora: Quem vai reciclar o lixo?

A maioria levanta a mão.

Pesquisadora: Porque reciclar o lixo?

Am2: Para ela não se mistura com o lixo orgânico?

Pesquisadora: Porque ele não pode misturar?

Am3: Por causo que ele tem que ser reciclado.

Pesquisadora: E porque ele tem que ser reciclado?

Af3: Por causa dos materiais.

Pesquisadora: Porque a gente separa os materiais? Se a gente vai ali e compra tudo pronto separado?

Am3: Pra ajudar a natureza.

Pesquisadora: Porque a gente tem que ajudar a natureza?

Risadas, por conta de tanto porquê.

Pudemos perceber que a cada colocação as crianças refletiam e se esforçavam para encontrar a melhor solução até que chegaram ao cerne do dilema que foi a produção do lixo. Ao acionarmos a capacidade de reflexão também possibilitamos a capacidade criativa, que motivou ainda mais as crianças para participação.

Quando da exibição do segundo vídeo sobre a reportagem do Fantástico, se constatou que o conhecimento das crianças é preliminar relacionado ao processo de resíduos sólidos e dos danos que esses causam ao meio ambiente. O conhecimento que predomina sobre os resíduos sólidos é estanque, ou seja se limita a fases isoladas e à distinção dos objetos (PIAGET, 1932).

Não há compreensão do processo sistêmico de decomposição dos resíduos sólidos, lançados em locais impróprios e também das características específicas de decomposição de cada matéria (alimentos, papel, garrafa PET e vidro). Elas ainda veem as coisas de forma atomística, Piaget (1976), isto justifica porque há quantidade de alunos com conhecimento ambiental "preliminar" sobre o meio ambiente (VESTENA, 2011).

Para exemplificar este fato, apresentamos a seguir fala de uma das crianças:

Pesquisadora: O que acontece com o papel, o plástico e o vidro quando são jogados em terrenos abandonados?

Am1: O papel é mais fácil pra se decompor porque vem a chuva e vai diluí, mais o vidro e o plástico vai demorar muito tempo.

Af1: O papel se decompõe mais rápido.

Pesquisadora: Muito lixo tem sido jogado nas ruas, da cidade. Quando as pessoas jogam lixo nas ruas, o que você acha que acontece?

Am1: Entope bueiros.

\begin{tabular}{l|l} 
Revista RBBA & Revista Binacional Brasil Argentina
\end{tabular} 
Af1: Centenas de enxurradas e vai para dentro das casas.

Pesquisadora: Os lixos jogados nas ruas podem ser reaproveitados? Se sim, conte-me como? Se não, por quê?

Am1: Sim, da pra reciclar, fazer adubo.

Bm1: Qualquer coisa, o vidro pode quebrar e alguém passar por la e se machucar.

Bf1: O papel vai sumir, tipo ele vai ficando em pedacinho até sumir.

Bm1: Sim, da pra reciclar, fazer carrinhos, hortas.

Bf1: Sim, meu tio faz panelinha, bule, chaleira ela faz o joguinho todo.

Durante as atividades pôde-se perceber as características dos estudos de Piaget, uma vez que se evidenciou que a transmissão do conhecimento está diretamente ligada ao ambiente, a história e a cultura. Isso porque ela começa na construção do espaço na vida cotidiana.

O dilema da destinação do lixo fez com que elas buscassem equilibrar suas ações assimilando outras formas de destinação, como a coleta seletiva que é a solução encontrada na colônia, mas que não acontece na comunidade quilombola.

Percebemos que as crianças pesquisadas têm consciência sobre diversas questões do meio ambiente, portanto conheciam os danos causados pela poluição. Grande parte das crianças conhecia os materiais e processos que são usados para dar origem ao papel, plástico, etc. e afirmaram que faziam a reciclagem dos mesmos, além disso o lixo orgânico, segundo elas é usado para adubo de hortas.

Não houve interferências das professoras, dessa forma as crianças responderam espontaneamente e demonstraram grande interesse pelo vídeo e pelos questionários, participando e comentando livremente, exceto as meninas quilombolas que sob os olhares censuradores das outras crianças, em especial dos meninos brancos da colônia, calavam-se. Algumas vezes parecia que haveria manifestação, mas, isso não se concretizou (grifo nosso).

Para as meninas quilombolas, que estão se subordinando à coação do professor, como também pela coerção percebida pelos demais alunos em sala de aula, nesta relação, o comportamento que acaba por ser manifestado por elas é o de enganação, imitação ou conformismo, pois elas se mantiveram em silêncio. A fundo, segundo Munari (2010), Piaget "propõe uma escola sem coerção, na qual o aluno é convidado a experimentar ativamente, para reconstruir por si mesmo, aquilo que tem de aprender." (MUNARI, 2010, p.18)

Nesse sentido, o método clínico se demonstrou meio importante de localizar o movimento do conhecimento das crianças em sala de aula, como também meio de evidenciar 
o silêncio e a partir dele o entendimento. Com a proposição dos dilemas ficou perceptível no conteúdo e omissão de falas a opressão a que são submetidas as crianças quilombolas em especial as meninas. Seja pelo não posicionamento dos professores e diretores para as questões sociais, graves, ou ainda, pela violência latente, por haver o desprezo pela diversidade escolar, que pode estar camuflando uma tentativa de deixar no esquecimento a cultura quilombola o que se pôde-se constatar é que a convivência entre culturas causa conflitos escolares graves, necessários de acompanhamento e enfrentamento urgentes.

Nesse sentido a escola que recebe crianças quilombolas, seja por educação convencional ou por educação quilombola precisa de um modelo claro, sendo esse apelo urgente. Montoya comenta que "apesar das diferenças que separam os conhecimentos físicos dos sociais e culturais, esses últimos se desenvolvem e são adquiridos de forma análoga aos primeiros." Essa analogia segundo o autor,

[...] obedece ao fato que tal como o conhecimento físico, o conhecimento social e cultural exige abstrações empíricas, no sentido de extrair caracteres e particularidades do mundo exterior, e inserção desses dados em sistema de relações lógicas-matemáticas. Deve-se igualmente ao fato de que as composições sucessivas, efetuadas pelo sujeito, realizam-se numa seqüência de complexidade e objetividade progressiva. (MONTOYA, 2004, p.172-173)

Portanto, há nesse momento que se partir para o desenvolvimento de conceitos que considerem essa prática ativa da Educação Quilombola - EQ como uma educação que manuseia, experimenta, constrói e julga, fundamentada em regras morais que lhe são próprias e que precisam ser consideradas na concepção de um projeto educacional que contemple um currículo rico em diversidade, como é o universo afro brasileiro.

Para Ferreiro, "nenhuma prática pedagógica é neutra. Todas estão apoiadas em certo modo de conceber o processo de aprendizagem e o objeto dessa aprendizagem" (2000, p.31). Além disso, é preciso que o educador, assim como postula Piaget, "deva adaptar seu ponto de vista ao da criança. Uma tarefa que não é nada fácil” (FERREIRO, 2000, p.61).

A escola tem o dever, a partir dos valores especificamente pedagógicos que orientam sua prática, de ampliar e aprofundar no aluno o seu processo de aquisição de conhecimentos. O que se propõe é o respeito às matrizes culturais a partir das quais se constrói a identidade dos alunos, com a atenção voltada para tudo aquilo que vá resgatar suas origens e sua história (o que também significa respeitar os direitos humanos!), como condição de afirmação de sua dignidade enquanto pessoa, e da especificidade da herança cultural que ele carrega, como parte da infinita diversidade que constitui a riqueza do ser humano. Esse é um valor que se revela essencial numa 
sociedade marcada por uma formação pluriétnica e multicultural. (MOURA In BRASIL, 2006, p. 264)

O construtivismo de Piaget pode auxiliar nisso, no entendimento de uma EQ inovadora, pois como uma teoria que preza pela construção do conhecimento e desenvolvimento do julgamento moral das crianças de forma operacional, onde suas implicações independem de sua origem sendo essa, na perspectiva do autor, respeitada previamente quando buscamos a compreensão da criança íntegra, no seu meio social e cultural.

\section{Referências}

BRASIL, Casa Civil. Constituição da República Federativa do Brasil. Brasília: 1988.

BRASIL. Secretaria Especial de Políticas de Promoção da Igualdade Racial - SEPPIR. I Plano Nacional de Desenvolvimento Sustentável dos Povos e Comunidades Tradicionais de Matriz Africana. Brasília: 2013.

BRASIL. MEC - Ministério da Educação. SEPPIR - Secretaria Especial de Políticas de Promoção da Igualdade Racial. Saberes e fazeres, v.3: modos de interagir / coordenação do projeto Ana Paula Brandão. - Rio de Janeiro: Fundação Roberto Marinho, 2006.

BRASIL. MEC - Ministério da Educação. SEPPIR - Secretaria Especial de Políticas de Promoção da Igualdade Racial. Saberes e fazeres, v.2: modos de sentir / coordenação do projeto Ana Paula Brandão. - Rio de Janeiro: Fundação Roberto Marinho, 2006.

BRASIL. MEC - Ministério da Educação. SEPPIR - Secretaria Especial de Políticas de Promoção da Igualdade Racial. Saberes e fazeres, v.1: modos de ver / coordenação do projeto Ana Paula Brandão. - Rio de Janeiro: Fundação Roberto Marinho, 2006.

CAMPOS, D. M. de S. Introdução a pesquisa em psicologia: aspectos metodológicos. Petrópolis: Vozes, 1932.

CARRAHER, T. N. O método clínico: usando os exames de Piaget. São Paulo: Cortez, 1994.

DEVAL, Juan. Introdução à Prática do Método Clínico, descobrindo o pensamento das crianças. Porto Alegre: Artmed, 2002.

FACHIN, O. Fundamentos de Metodologia. 5a ed. São Paulo: Saraiva, 2006.

FERREIRO, Emilia. Reflexões Sobre Alfabetização. São Paulo: Cortez, 2000.

LA TAILlE, Yves de. Moral e Ética: dimensões intelectuais e afetivas. Porto Alegre: Artmed, 2006. 
MONTOYA, A. O. D. Contribuições da Psicologia e Epistemologia Genéticas para a Educação. In: Introdução à Psicologia da Educação: seis abordagens. p. 157-185. São Paulo: Avercamp, 2004.

MOURA, G. Aprendizado nas Comunidades Quilombolas: Currículo Invisível. In: Dimensões da inclusão no ensino médio: mercado de trabalho, religiosidade e educação quilombola. Brasília: 2006.

MUNARI, A. Jean Piaget. Coleção Educadores. Recife: Fundação Joaquim Nabuco, Editora Massangana, 2010.

O’DWYER, Eliane Cantarino (Org.). Terra de quilombos. Rio de Janeiro: Associação Brasileira de Antropologia, 1995.

PIAGET, Jean. O julgamento moral da criança. São Paulo: Editora Mestre Jou, 1932.

Cinco Estudos de Educação Moral... let al| organizador Lino de Macedo. São Paulo: Casa do Psicólogo, 1996. 1974.

Epistemologia Genética e Pesquisa Psicológica. Rio de Janeiro: Freitas Bastos,

Introduction à epistemologie génétique. II. La penseé physique. Paris: Presses Universitaires de France, 1949.

SASSO, B. A.; DE MORAIS, A. O Egocentrismo Infantil na Perspectiva de Piaget e Representações de Professoras. Scheme, Revista Eletrônica de Psicologia e Epistemologia Genética. Volume 5 Número 2. p.24 - 51. Ago-Dez/2013. Disponível em: www.marilia.unesp.br/scheme. Acessado em: 10/11/2014.

SCOTT, J. Gênero: Uma Categoria Útil de Análise Histórica. Revista Educação e Realidade. n. 20, p. 71-99. Porto Alegre: 1995.

VESTEnA, Carla Luicane Blum. Piaget e a Questão Ambiental: sujeito epistêmico, diagnóstico e considerações educacionais. São Paulo: Cultura Acadêmica, 2011.

\section{Notas}

\footnotetext{
${ }^{\text {i }}$ Disponível no site: http://elplasticomata.com/ Acesso em 12.11.2019.

ii Disponível em http://www.youtube.com/watch?v=XwvYzmk-NjY .
} 


\section{Sobre as autoras}

Juliana Berg é bolsista CaPes, doutoranda em Educação pelo PPGE/Universidade Federal do Paraná; Estagiária em Pesquisa pela Universidade Portucalense, Portugal; Mestre em Educação pela Universidade Estadual do CentroOeste; é Pesquisadora Internacional no Grupo de Trabalho Identity of Psychology e integrante do Núcleo de Red Internacional de Escuelas Creativas (RIEC) e Asociación de Escuelas Creativas (ADEC) de iniciativa da Universidade de Barcelona, Barcelona-Espanha. É também coordenadora do Núcleo de Escolas Criativas RIEC Unicentro. Pesquisa nas áreas de Criatividade, Teoria da Complexidade, Teoria da Mente e Moralidade, Comunicação e Gênero.

Endereço eletrônico: bergjuliana@gmail.com

Carla Luciane Blum Vestena é Bolsista produtividade da F.A. Pesquisadora LAPE; é Docente Associada "A" da Universidade Estadual do Centro-Oeste (UNICENTRO); Docente colaboradora do Programa de Pós-graduação em Educação pela Universidade Federal do Paraná (UFPR). Tem Pós-doutoramento na [School of Education], Durham University - UK (2016-2017). É Doutora em Educação pela Universidade Estadual Paulista Júlio de Mesquita Filho (UNESP-Marília-SP). É membro da Sociedade Brasileira Jean Piaget, SBJP, Brasil. É integrante do Núcleo de Red Internacional de Escuelas Creativas (RIEC) e Asociación de Escuelas Creativas (ADEC) de iniciativa da Universidade de Barcelona, BarcelonaEspanha.

Endereço eletrônico: clbvestena@gmail.com 